\title{
Decreasing trend in Toxoplasma seroprevalence among pregnant women in Kuwait
}

Nourah Al-Shammari ${ }^{1}$ and Jamshaid Iqbal ${ }^{1}$

${ }^{1}$ Department of Microbiology, Faculty of Medicine, Kuwait University, Kuwait (Correspondence to: J. Iqbal: iqbal@hsc.edu.kw).

\begin{abstract}
Background: Primary toxoplasmosis early in pregnancy may cause fetal pathology. Understanding and documenting serological epidemiology and associated risk factors about Toxoplasma gondii infection is crucial to offering appropriate interventions to prevent such fetal pathology.
\end{abstract}

Aims: To determine the seroepidemiological status and major risk factors associated with T.gondii infection among pregnant women in Kuwait.

Methods: This was an observational cross-sectional multicentre descriptive study. Blood samples and sociodemographic information were collected from 280 pregnant women attending antenatal clinics. The blood samples were screened with VIDAS Toxo-IgG/IgM and SERIONE IgG/IgM and IgG avidity assays to detect T. gondii-specific antibodies.

Results: Overall seroprevalence of T. gondii IgG and IgM antibodies among pregnant women was $12.5 \%$ and $2.1 \%$, respectively. Only two IgG-positive women had low IgG avidity suggesting acute infection. No significant association was observed between seroprevalence and known risk factors for toxoplasmosis.

Conclusions: This is believed to be the first study of T. gondii infection and its associated risk factors among pregnant women in Kuwait. The seroprevalence rate of $12.5 \%$ is one of the lowest in the Middle East. There was no significant association between T. gondii seroprevalence and known risk factors. This may have been due to the high education level (>94\%) among pregnant women that may have changed women's behavior during pregnany, thus minimizing transmission of toxoplasmosis.

Keywords: Kuwait, pregnant women, risk factors, seroprevalence, Toxoplasma gondii

Citation: Al-Shammari N; Iqbal J. Decreasing trend in Toxoplasma seroprevalence among pregnant women in Kuwait. East Mediterr Health J. 2021;27(1):67-75. https://doi.org/10.26719/emhj.20.082

Received: 25/11/19; accepted: 16/01/20

Copyright (C) World Health Organization (WHO) 2021. Open Access. Some rights reserved. This work is available under the CC BY-NC-SA 3.0 IGO license (https://creativecommons.org/licenses/by-nc-sa/3.o/igo).

\section{Introduction}

Toxoplasmosis is caused by an obligate intracellular opportunistic protozoan parasite, Toxoplasma gondii, which has a worldwide distribution, affecting about one third of the human population $(1,2)$. Humans are infected by ingesting cysts from undercooked meat, or by consuming water or food contaminated with infectious oocysts (3). Approximately $10-15 \%$ of infected cases may develop flulike symptoms; however, T. gondii may cause severe consequences in patients with supressed immune systems (4).

Serological testing to detect specific anti-T. gondii IgG and/or IgM antibodies is the first step in the diagnosis of toxoplasmosis; however, it may be difficult to distinguish between primary and chronic infection by a single test. IgG appears later than IgM and is usually detectable within 1-2 weeks after infection, reaching a peak reached within 3-6 months after acute infection, and remaining detectable throughout life. A second sample within 2-3 weeks showing a 2 -fold rise in IgG titre or positive IgM indicates recent/acute infection. A recently introduced IgG avidity test can distinguish between acute and chronic infection within a window of 3 months, and thus gives more reliable information on the status of acute/ chronic infection, which is crucial for management of pregnant women.

Based on serological surveys, the incidence of primary maternal toxoplasma infection ranges from 1 to 8 per 1000 pregnancies in different populations (5). Generally, > $80 \%$ of pregnant women with acute primary infection do not present with any symptoms. However, the infection may be transmitted to the fetus through the placenta, causing a wide range of serious congenital conditions, especially during the first trimester $(1,6,7)$. It is therefore important to detect infection early in pregnancy to prevent congenital fetal infection and minimize the risk of serious congenital conditions $(8,9)$.

A number of epidemiological surveys carried out among women of childbearing age have repeatedly shown variation in the prevalence of toxoplasmosis, ranging from 7.5 to $92.5 \%$ in different parts of the world: 9-11\% in the United States of America (USA) and 9.1$67 \%$ in Europe, with France being at the upper end. A decline in seroprevalence of $\mathrm{T}$. gondii infection has been reported recently in the USA and some other developed countries (10). A high incidence of seroprevalence of up to $92.5 \%$ was reported in Ghana (11), but a moderate to low seroprevalence was reported in most South Asian 
countries (12). A recent systematic review and metaanalysis showed a seroprevalence of $27.8 \%$ among Saudi women of reproductive age (13), while a higher prevalence of 46.2-64.3\% was observed among pregnant women in Yemen (14). Although there is a good understanding of the risks of infection transmission among pregnant women, more detailed studies are needed to understand toxoplasmosis among the general population (15).

Kuwait is demographically diverse with up to $70 \%$ of the total population coming from other parts of the world. Information on the prevalence of toxoplasmosis and its associated risk factors among pregnant women in Kuwait is limited. A retrospective cohort study conducted $>10$ years ago reported an incidence of $53.1 \%$ for IgG and $13.8 \%$ for IgM in Kuwait, but there was no report on the risk factors associated with toxoplasmosis (16). The present study aimed to determine the current seroepidemiological status of toxoplasmosis and the major risk factors among pregnant women in Kuwait.

\section{Methods}

\section{Study design and population}

This was an observational, cross-sectional, multicentre descriptive study. We used online statistical calculators to enter our values for $95 \%$ confidence interval, power $(80 \%)$, margin of error (5\%) and population size of 4.1 million individuals. Based on these criteria, the minimum sample size was calculated as 280 on the basis of previously reported incidence of $13.8 \%$ of active infection warranting therapeutic intervention (16). Kuwait is a small country with no distinction between rural and urban regions; thus, the geographical environment, sociodemographic characteristics and lifestyle of its population are similar throughout the country. Therefore, a systematic random sampling procedure was utilized to enrol pregnant women attending antenatal clinics at 3 major hospitals (Maternity Hospital, Al-Jahra Hospital and Al-Adan Hospital) in Kuwait between October 2017 and February 2019.

\section{Sample and data collection}

Venous blood $(2.5 \mathrm{ml})$ was collected in a plain tube from all enrolled women and transported to the Parasitology Laboratory in the Faculty of Medicine, Kuwait University. Sera were collected from the blood and stored at $-20^{\circ} \mathrm{C}$ in small tubes until analysis. Relevant sociodemographic characteristics and exposure to known risk factors were recorded using an approved structured questionnaire mostly with predetermined definitive closed-end answers.

\section{Enzyme immunoassays}

A series of immunoassays was carried out on the specimens to detect T. gondii-specific IgG and IgM and IgG avidity. All 280 blood specimens were screened for T. gondii-specific IgG and IgM antibodies using the recently introduced SERION ELISA classic assay (Institute Virion\ Serion GmbH, Würzburg, Germany). Additionally, 100 subsamples were selected randomly and tested for IgG and IgM using VIDAS Toxo-IgG and IgM assays (bioMer- ieux, Durham, NC, USA) to compare the performance of the SERION and VIDAS assays. All IgG-positive samples were tested for IgG avidity.

\section{Anti-T. gondii IgG and IgM antibody detection by SERION ELISA}

T. gondii IgG/IgM antibodies were measured in each blood specimen using the SERION ELISA classic assay. Optical density (OD) was analysed using the SERION software. Each test run included a substrate blank, positive, negative and two standard sera to determine precision and accuracy. The test results for IgG were interpreted as follows: $\leq 5 \mathrm{IU} / \mathrm{ml}$, negative; 10-20 IU/ml, equivocal; and $>20 \mathrm{IU} / \mathrm{ml}$, positive. The test results for IgM were interpreted as follows: $\leq 100 \mathrm{IU} / \mathrm{ml}$, negative; 100-350 IU/ml, equivocal; and > $350 \mathrm{IU} / \mathrm{ml}$, positive.

\section{Ig $G$ avidity-ELISA detection by SERION ELISA classic}

The IgG-avidity test distinguished past and newly acquired infections within a window of 3 months and thus gives reliable information on the status of acute/active infection. The test results for IgG avidity index were interpreted as follows: < 45\% correlated with acute primary infection; 45-50\%, borderline range; and > 50\% indicated previous infection.

\section{VIDAS Toxo-Ig G, IgM and IgG avidity}

Anti-T. gondii IgG, IgM and IgG avidity was measured using the fully automated VIDAS instrument. Anti-T. gondii IgG or IgM antibodies were analysed following catalysis by conjugated enzyme-labelled mouse monoclonal anti-human IgG or IgM antibodies coated on the plate. $\mathrm{OD}_{450}$ was measured and the results were automatically calculated by the VIDAS instrument. To determine IgG avidity, the diluted specimens were added to the VIDAS Toxo-IgG avidity test strips that contained $6 \mathrm{M}$ urea to remove the low-avidity IgG antibodies from their binding sites, while the antibodies with high avidity remained bound to the solid phase. The ratio between the quantity of high-avidity antibodies (test strip) and total antibodies (reference strip) provided an index. A low avidity index < 0.2 indicated acute infection and $>0.25$ excluded primary infection within the previous 16 weeks.

\section{Statistical analysis}

Data collected from all pregnant women were correlated with their corresponding OD values to determine the risk factors associated with T. gondii infection. Data were coded and analysed using SPSS version 25 software. The $\mathrm{c} 2$ and nonparametric tests for $\geq 2$ independent samples, Mann-Whitney and Kruskal-Wallis tests were used to evaluate the possible differences between various diagnostic assays and risk factors. $\mathrm{P}<0.05$ was considered as statistically significant.

\section{Ethical considerations}

All women participating in this study gave written informed consent with strict confidentiality of their data 
and test results. All women were informed of their serological status and those with acute infection were advised for immediate consultation with their attending physicians. The study was approved by the Ethical Committee for the Protection of Human Subjects in Research, Kuwait University and the Kuwaiti Ministry of Health, under reference no. 187/2014, which is in agreement with the Code of Ethics of the World Medical Association.

\section{Results}

\section{Participant characteristics}

The demographic data of all participants are presented in Table 1. Most women were aged $30-39$ years $(n=151$; $53.9 \%)$ with a median age of 31.2 years. The interquartile range $\left(Q_{3}-Q_{1}\right)=10.548$; where $\left(Q_{1}=25.309, Q 2=31.221\right.$ and $\mathrm{Q} 3=35.857)$. Most women were Kuwaiti nationals $(n=$ 188; 67.1\%). Most of the non-Kuwaiti women had spent $\geq 7$ years in Kuwait. Most women had completed their secondary and higher education $(n=264 ; 94.3 \%)$ and 137 (48.9\%) were Government employees. Two hundred and five women $(73 \%)$ were multigravida and $162(57.9 \%)$ had no history of abortion. Most women were in the third trimester $(n=123 ; 43.9 \%)$.

\section{Prevalence of Ig G and IgM antibodies}

A total of $35(12.5 \%)$ specimens were positive for IgG antibodies (Table 2). Thirteen (4.6\%) gave an equivocal result and $232(82.9 \%)$ were negative for IgG antibodies. T. gondii-specific IgM antibodies were detected in only $6(2.1 \%)$ women who were also positive for IgG antibodies; one woman each was in the first or second trimester and 4 were in the third trimester. All 35 IgG-positive women were also screened for IgG avidity to determine their infection status. Only 2 women who were IgG+ and IgM+ showed low IgG avidity index, suggesting an acute infection rate of $5.7 \%$ among the IgG-positive women and $0.71 \%$ among all the enrolled women. Both of these women were in their third trimester. The remaining 33 women had high IgG avidity, indicating chronic infection. Twenty-one of the $35 \mathrm{IgG}+$ women $(60 \%)$ and all $6 \mathrm{IgM}+$ women attended the Maternity Hospital. There was a positive correlation between IgG and IgM antibodies $(r=0.108)$, and a significant negative correlation between IgG/IgM antibodies and IgG avidity index; $\mathrm{r}=-0.399$ and -0.400 , respectively.

The sociodemographic and behavioral risk factors, obstetric and serological status of the 2 women with acute toxoplasmosis are presented in Table 3. Both women had high IgG and IgM antibody titres and low IgG avidity index status, attended the Maternity Hospital and had a history of eating uncooked meat, but their contact with cats was variable.

A total of 100 randomly selected samples were also screened with VIDAS Toxo-IgG, IgM and IgG avidity assays which were used earlier in a retrospective study conducted in Kuwait $>10$ years ago (16). No significant difference was observed in the sensitivity and specificity of SERIONE and VIDAS assays to detect T. gondii-specific

\begin{tabular}{|c|c|}
\hline Characteristic & No. (\%) \\
\hline \multicolumn{2}{|l|}{ Age group (years) } \\
\hline$<20$ & $9(3.2)$ \\
\hline $20-29$ & $105(37.5)$ \\
\hline $30-39$ & $151(53.9)$ \\
\hline$>40$ & $15(5.4)$ \\
\hline \multicolumn{2}{|l|}{ Country of origin } \\
\hline Kuwait & $188(67.1)$ \\
\hline Gulf Countries & $32(11.4)$ \\
\hline Africa & $22(7.9)$ \\
\hline India & $21(7.5)$ \\
\hline Eastern Mediterranean Region & $17(6.1)$ \\
\hline \multicolumn{2}{|l|}{ Educational status } \\
\hline Uneducated & $4(1.4)$ \\
\hline Educated & $12(4.3)$ \\
\hline Secondary school \& above & $264(94.3)$ \\
\hline \multicolumn{2}{|l|}{ Occupation } \\
\hline Housewife & $85(30.4)$ \\
\hline Private employee & $30(10.7)$ \\
\hline Government employee & $137(48.9)$ \\
\hline Other & $28(10.0)$ \\
\hline \multicolumn{2}{|l|}{ Gravidity } \\
\hline Primigravida & $75(26.8)$ \\
\hline Multigravida & $205(73.2)$ \\
\hline \multicolumn{2}{|l|}{ Gestational period } \\
\hline First trimester & $60(21.4)$ \\
\hline Second trimester & $97(34.6)$ \\
\hline Third trimester & $123(43.9)$ \\
\hline \multicolumn{2}{|l|}{ History of abortion } \\
\hline No & $162(57.9)$ \\
\hline Yes & $118(42.1)$ \\
\hline \multicolumn{2}{|l|}{ Contact with domestic cats } \\
\hline No & $240(85.7)$ \\
\hline Yes & $40(14 \cdot 3)$ \\
\hline \multicolumn{2}{|l|}{ Consumption of undercooked meat } \\
\hline No & $178(63.6)$ \\
\hline Yes & $102(36.4)$ \\
\hline \multicolumn{2}{|l|}{ Hand washing } \\
\hline Sometimes & $12(4.3)$ \\
\hline Yes & $268(95.7)$ \\
\hline
\end{tabular}

IgG and IgM antibodies and IgG avidity index (data not shown).

\section{Risk factors associated with T. gondii IgG- positive pregnant women}

Table 4 shows the association of major risk factors with $\mathrm{T}$. gondii seropositivity. There was no significant association 


\begin{tabular}{|c|c|c|c|}
\hline \multirow[t]{2}{*}{ Hospital } & \multirow{2}{*}{$\begin{array}{l}\text { Total cases } \\
\text { screened }\end{array}$} & \multicolumn{2}{|c|}{ Seroprevalence } \\
\hline & & $\operatorname{IgG}(\%)$ & $\operatorname{IgM}(\%)$ \\
\hline Maternity & 98 & $21(21.4 \%)(P=0.004)$ & $6.0(6.1 \%)$ \\
\hline Al-Jahra & 68 & $6(8.8 \%)$ & 0 \\
\hline Al-Adan & 114 & $8(7.0 \%)$ & 0 \\
\hline Total & 280 & $35(12.5 \%)$ & $6(2.1 \%)$ \\
\hline
\end{tabular}

of any particular age group with seropositivity, although 21 of $35(60 \%)$ seropositive women were aged 30-39 years, and 11 women (31.4\%) were aged 20-29 years. Similarly, no significant association was observed between seropositivity and gravidity or history of abortion. Contact with domestic cats and eating undercooked meat showed no significant association with T. gondii seropositivity. There was no significant association between T. gondii seropositivity and age, occupation and gestational age. However, the site of sample collection (Maternity Hospital) and the country/region of origin (Kuwaiti) were significantly associated with $\operatorname{IgG}$ seropositivity $(P=0.004$ and $P=0.014$, respectively).

\section{Discussion}

Understanding the seroepidemiology and associated risk factors for T. gondii infection among pregnant women is crucial to offer appropriate interventions to prevent congenital fetal infection. In this study, the overall seroprevalence of T. gondii IgG- and IgM-specific antibodies among pregnant women in Kuwait was $12.5 \%$ and $2.1 \%$, respectively. These rates were significantly lower than the incidence of $53.1 \%$ for IgG and $13.8 \%$ for IgM reported earlier by a retrospective cohort study $>10$ years ago (16), although different screening assays were used in the 2 studies. We tested 100 randomly selected samples with the SERION and VIDAS assays and there was no signifi- cant difference in their sensitivity and specificity to detect T. gondii-specific antibodies. Perhaps more awareness through effective health education campaigns and better hygiene may have contributed to the decreasing trend in toxoplasmosis seroprevalence among pregnant women in Kuwait. Surprisingly, the rate reported in the present study was even lower than previously reported in some neighbouring countries. A comprehensive review of seroepidemiological studies of toxoplasmosis among pregnant women in the Middle East showed a wide range of rates from $24.1 \%$ in Jazan Province, Saudi Arabia (17) to $82.6 \%$ in Beirut, Lebanon (18) (Table 5). A recent systematic review and meta-analysis of $>13000$ Saudi women of childbearing age and a meta-analysis of 43 Iranian studies among pregnant women showed an overall toxoplasmosis seroprevalence of $27.8 \%$ and $41.3 \%$, respectively $(13,19)$. Similarly, several prior studies in other countries across the Middle East reported higher rates of T. gondii seroprevalence in pregnant women and/or those of childbearing age: including $47.0 \%$ in Jordan (20), 46.2\% in Yemen (14), 38.0\% in Riyadh, Saudi Arabia (8), 35.1\% in Qatar (21) and $33.7 \%$ in Egypt (22).

This variation in prevalence between countries within a region may be attributed to differences in socioeconomic status, geographic conditions and hygienic practices. Currently, the seroprevalence and potential risk factors for T. gondii infection are not fully understood. Therefore,

Table 3 Sociodemographic and behavioral risk factors, obstetric and serological status of 2 women with acute Toxoplasma gondii infection

\begin{tabular}{lll}
\hline Factors & Case 1 & Case 2 \\
\hline Sociodemographic factors & & 27 years \\
$\quad$ Age & 23 years & Armenian \\
Nationality & Lebanese & $>7$ years \\
Resident in Kuwait & $>10$ years & High school \\
$\quad$ Education status & High school & Third trimester \\
Obstetric history & & Primigravida \\
$\quad$ Gestational age & Third trimester & No \\
$\quad$ Gravity & Primigravida & No \\
History of abortion & Yes & Yes \\
Behavioral factors & & Yes \\
$\quad$ Contact with domestic cats & Yes & \\
Eating undercooked meat & Yes & $95.497 \mathrm{IU} / \mathrm{ml}(1.187)$ \\
$\quad$ Hand washing & Yes & $2347.776 \mathrm{IU} / \mathrm{ml}$ \\
Serological status & & Low, 43\% \\
IgG & $137.065 \mathrm{IU} / \mathrm{ml}(2.094)$ & $1205.252 \mathrm{IU} / \mathrm{ml}$ \\
IgM & Low, 32\% & \\
IgG avidity status & &
\end{tabular}

$\mathrm{OD}_{450}=$ optical density at $450 \mathrm{~nm}$. 


\begin{tabular}{|c|c|c|c|}
\hline Variables & $\begin{array}{c}\text { Positive }(n=35) \\
n(\%)\end{array}$ & $\begin{array}{c}\text { Negative }(n=245) \\
n(\%)\end{array}$ & $\mathbf{P}$ \\
\hline \multicolumn{4}{|c|}{ Age groups (years) } \\
\hline$<20$ & 0 & $9(100)$ & \multirow{4}{*}{0.290} \\
\hline $20-29$ & $11(10.5)$ & $94(89.5)$ & \\
\hline $30-39$ & $21(13.9)$ & $130(86.1)$ & \\
\hline$>40$ & $3(20.0)$ & $12(80.0)$ & \\
\hline \multicolumn{4}{|l|}{ Nationality } \\
\hline Kuwaiti & $16(8.5)$ & $171(91.5)$ & \multirow[t]{2}{*}{0.014 * } \\
\hline Non-Kuwaiti & $19(20.4)$ & $74(79.6)$ & \\
\hline \multicolumn{4}{|l|}{ Gravidity } \\
\hline Primigravida & $10(13.3)$ & $65(86.7)$ & \multirow[t]{2}{*}{0.799} \\
\hline Multigravida & $25(12.2)$ & $180(87.8)$ & \\
\hline \multicolumn{4}{|c|}{ History of abortion } \\
\hline No & $17(10.5)$ & $145(89.5)$ & \multirow[t]{2}{*}{0.234} \\
\hline Yes & $18(15.3)$ & $100(84.7)$ & \\
\hline \multicolumn{4}{|c|}{ Contact with domestic cats } \\
\hline No & $31(12.9)$ & $209(87.1)$ & \multirow[t]{2}{*}{0.606} \\
\hline Yes & $4(10.0)$ & $36(90.0)$ & \\
\hline \multicolumn{4}{|c|}{ Eating undercooked meat } \\
\hline No & $25(14.0)$ & $153(86.0)$ & \multirow[t]{2}{*}{0.302} \\
\hline Yes & $10(9.8)$ & $92(90.2)$ & \\
\hline \multicolumn{4}{|l|}{ Hand washing } \\
\hline Sometimes & $3(25.0)$ & $9(75.0)$ & \multirow[t]{2}{*}{0.178} \\
\hline Yes & $32(11.9)$ & $236(88.1)$ & \\
\hline
\end{tabular}

*Significant risk factor for T. gondii infection.

understanding the variation in prevalence of T. gondii infection in a geographically close area, like the Gulf Region, is important for infection prevention and control.

In this study, seropositivity to toxoplasmosis started in women aged $20-29$ years (31.4\%), increased to $60 \%$ at age 30-39 years, and then decreased among those aged $>40$ years. However, there was no significant association between seroprevalence and the older age group. In contrast to the current study, a number of studies from various regions and a recent review of studies documenting potential risk factors related to seroepidemiological status of $T$. gondii infection in several Arab and African countries showed a significant association between T. gondii seropositivity and ageing $(17,23-25)$. The possible reason for this association is still not clear. In countries with moderate to high endemicity, lack of awareness of potential risk factors may predispose older people to toxoplasmosis and they then usually maintain a steady level of anti-T. gondii antibodies throughout life. However, in this study, we detected a low level of seropositivity (12.5\%) to toxoplasmosis and little or no exposure to risk factors. Therefore, it was not surprising to detect lower seropositivity among pregnant women in the older age group.
Additionally, other risk factors associated with toxoplasmosis (i.e., area of residence, contact with domestic cats, cultural practices and economic status) have been reported in previous studies. A systematic review and meta-analysis reported a significant association between toxoplasmosis and age, contact with cats and gestational age among Iranian women of child bearing age (26). However, we did not find a significant association between toxoplasmosis and most of these known risk factors. In agreement with our study, several studies have reported no significant association between toxoplasmosis and all or some of the reported risk factors $(13,27,28)$. This may be because of similar geographical environment and sociodemographic charactersitics, and particular lifestyles, culture and traditions prevailing in this part of the world.

We did not find evidence of any specific control measures or health education campaigns by health officials in Kuwait to prevent transmission of T. gondii. However, we believe that several factors may have been responsible for the current decreasing trend of toxoplasmosis seroprevalence in Kuwait. Kuwait is a small country with an economically affluent society and well-organized, highly developed infrastructure 


\begin{tabular}{|c|c|c|c|c|c|}
\hline Country & No. of cases & $\begin{array}{c}\text { IgG positivity } \\
\text { n (\%) }\end{array}$ & $\begin{array}{c}\text { IgM positivity } \\
\text { n (\%) }\end{array}$ & Assay & Refs \\
\hline Riyadh, Saudi Arabia & 2176 & $825(38.0)$ & NA & ELISA & (8) \\
\hline Saudi Arabia & 13597 & $(27.8)^{\mathrm{a}}$ & NA & ELISA & (13) \\
\hline Taiz, Yemen & 359 & $166(46.2)$ & $12(3.3)$ & ELISA & (14) \\
\hline Jazan, Saudi Arabia & 195 & $39(20.1)$ & $12(6.2)$ & ELISA & (17) \\
\hline Beirut, Lebanon & 2456 & $2029(82.6)$ & $46(1.8)$ & ELISA & (18) \\
\hline Islamic Republic of Iran ${ }^{\mathrm{b}}$ & 22644 & $(41.3)$ & (4.0) & ELISA & (19) \\
\hline Jordan & 280 & $133(47.0)$ & NA & IFA & (20) \\
\hline Qatar & 823 & $289(35.1)$ & $43(5.2)$ & ELISA & (21) \\
\hline Egypt & 364 & (33.7) & NA & ELISA & (22) \\
\hline Hebron, Palestine & 204 & $57(27.9)$ & $36(17.6)$ & EIA & (28) \\
\hline Kuwait & 224 & $119(53.1)$ & $31(13.8)$ & VIDAS & (16) \\
\hline Kuwait & 280 & $35(12.5)$ & $6(2.1)$ & $\begin{array}{l}\text { VIDAS } \\
\text { ELISA }\end{array}$ & This study \\
\hline
\end{tabular}

${ }^{a}$ Pooled estimation for T. gondii prevalence using a systematic review and meta-analysis of 20 studies.

${ }^{b}$ Pooled estimation for T. gondii prevalence using systematic review and meta-analysis of 43 studies.

IFA = immunofluorescence assay; NA = not available.

and health facilities throughout the country, providing timely diagnosis and treatment. Importantly, > 94\% of the pregnant women in this study had a higher education level that may have changed their behavior during pregnany, thus minimizing transmission of $\mathrm{T}$. gondii. A recent multicentre survey on toxoplasmosis among pregnant women in Poland showed that higher education level was significantly associated with better knowledge of toxoplasmosis (29).

There were limitations to our study and other confounding factors in comparing our results with other studies, including small sample size, and differences in assay systems and demographic characteristics. We enrolled a small sample of 280 pregnant women and their demographic characteristics may partially explain the disparity with the prevalence rate of $53.1 \%$ reported in 2002-2003. However, we believe that differences in assay systems and location of the study population do not account for significant differences in the seropositivity rate between the 2 studies. There was no significant difference in the sensitivity and specificity of SERION and VIDAS assays when testing 100 blood samples.
Furthermore, compared with the earlier study, 92 nonKuwaiti pregnant women were enrolled in our study but $>83 \%$ of these women had been residing in Kuwait for $>7$ years. Additionally, the sociodemographic characteristics and lifestyle of the population of Kuwait are similar throughout the country.

\section{Conclusion}

We detected a significantly lower T. gondii seroprevalence rate of $12.5 \%$ among pregnant women in Kuwait compared with $53.1 \%$ reported $>10$ years ago. This overall seroprevalence rate is one of the lowest among pregnant women in the Middle East. We did not find a significant association between T. gondii seroprevalence and the known risk factors. However, a higher education level among pregnant women (> 94\%) may have changed women's behavior during pregnany, thus minimizing transmission of infection. This study is important because it is believed to be the first to study the characteristics of $T$. gondii-seropositive pregnant women in Kuwait. Further surveys are needed to investigate the factors related to the decreasing trend of T. gondii seropositivity in Kuwait.

\section{Acknowledgement}

We gratefully acknowledge all the women who participated in the study.

Funding: College of Graduate Study and the Research Sector, Kuwait Univesrity, Kuwait, Project No. YM14/17.

Competing interests: None declared. 


\section{Tendance à la baisse de la séroprévalence de la toxoplasmose chez les femmes enceintes au Koweït}

\section{Résumé}

Contexte : La toxoplasmose primaire au début de la grossesse peut provoquer une pathologie fœetale. Il est essentiel de comprendre et de documenter l'épidémiologie sérologique et les facteurs de risque associés à l'infection à Toxoplasma gondii afin de pouvoir proposer des interventions appropriées pour prévenir ladite pathologie fœtale.

Objectifs : Déterminer le statut séroépidémiologique et les principaux facteurs de risque associés à l'infection à T. gondii chez les femmes enceintes au Koweit.

Méthodes: Il s'agissait d'une étude observationnelle transversale, multicentrique et descriptive. Des échantillons de sang et des informations socio-démographiques ont été recueillis auprès de 280 femmes enceintes consultant dans les dispensaires de soins prénatals. Les échantillons de sang ont été analysés au moyen des tests d'avidité VIDAS Toxo-IgG/ IgM et SERIONE IgG/IgM et IgG pour détecter les anticorps spécifiques de T. gondii.

Résultats : La séroprévalence globale des anticorps de la classe des IgG et IgM de T. gondii chez la femme enceinte était respectivement de $12,5 \%$ et $2,1 \%$. Seules deux femmes positives pour les IgG avaient une faible avidité des IgG évoquant la présence d'une infection aiguë. Aucune association significative n'a été observée entre la séroprévalence et les facteurs de risque connus de toxoplasmose.

Conclusions : Il s'agit apparemment de la première étude sur l'infection à T. gondii et ses facteurs de risque associés chez les femmes enceintes au Koweït. Le taux de séroprévalence de $12,5 \%$ est l'un des plus faibles au Moyen-Orient. Il n'y avait pas d'association significative entre la séroprévalence de T. gondii et les facteurs de risque connus. Cela peut être dû au niveau d'éducation élevé (supérieure à $94 \%$ ) chez les femmes enceintes, qui peut avoir modifié le comportement des femmes pendant la grossesse, minimisant ainsi la transmission de la toxoplasmose.

$$
\begin{aligned}
& \text { الجاه تنازلي لحالات الانتشار المصلي للمقوسة في صفوف النساء الحوامل في الكويت } \\
& \text { نورا الشمري، جمشيد إقبال } \\
& \text { الخلاصة }
\end{aligned}
$$

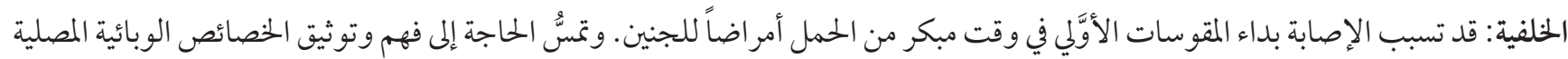

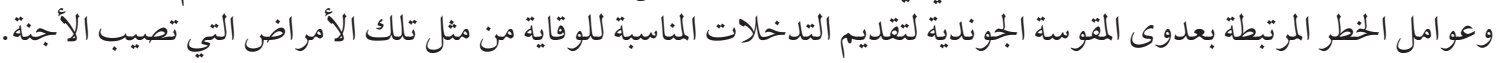
الأهداف: هدفت هذه الدراسة إلى تحديد الحالة المصلية الوبائية وعوامل الخطر الرئيسية المرتبطة بعدوى المقوسة الجوندية في صفوف النسية النساء الحوامل في الكويت.

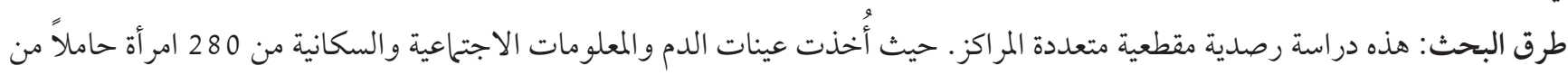

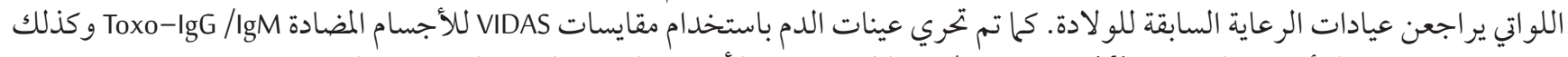

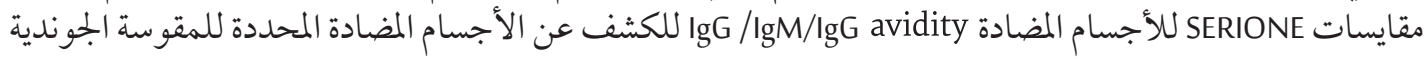

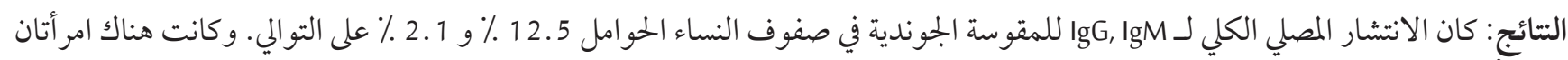

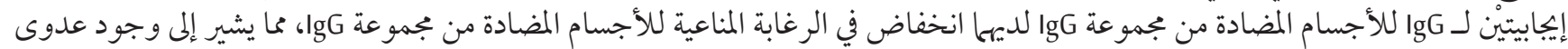

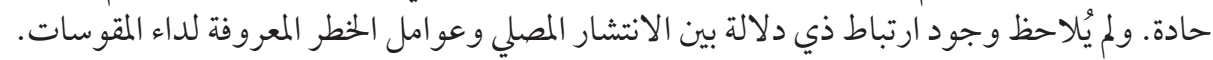

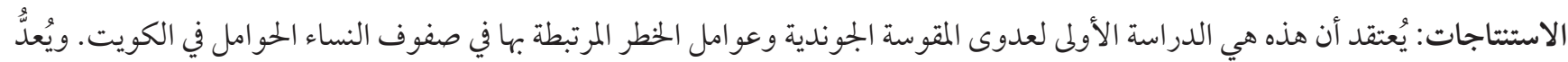

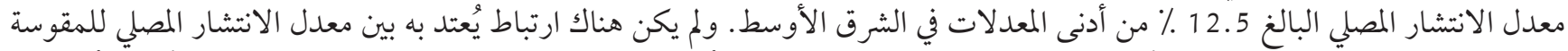

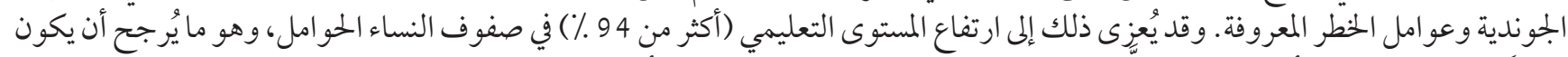

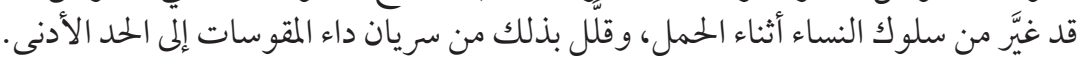




\section{References}

1. Weiss LM, Dubey JT. Toxoplasmosis: a history of clinical observations. Int J Parasitol. 2009 Jul 1;39(8):895-901. https://doi. org/10.1016/j.ijpara.2009.02.004

2. Liu Q, Wang Z, Huang S, Zhu, X. Diagnosis of toxoplasmosis and typing of Toxoplasma gondii. Parasit Vectors. 2015 May 28;8(1):292-306 http://dx.doi.org/10.1186/s13071-015-0902-6 PMID:26017718

3. Jones JL, Dubey JP. Foodborne toxoplasmosis. Clin Infec Dis. 2012 Sep 15;55(6):845-51. https://doi.org/10.1093/cid/cis508

4. Negussie A, Beyene E, Palani S. Toxoplasmosis and associated risk factors in antenatal clinic follow up pregnant women in selected health institutes of Jigjiga, East Ethiopia. Int J Trop Dis Health. 2017;21(3):1-7. https://doi.org/10.9734/ijtdh/2017/31177.

5. Gilbert RE, Peckham CS. Congenital toxoplasmosis in the United Kingdom: to screen or not to screen? J Med Screen. 2002;9(3):135-41. http://dx.doi.org/10.1136/jms.9.3.135 PMID:12370327

6. Fricker-Hidalgo H, Cimon B, Chemla C, Darde ML, Delhaes L, L'Ollivier C. et al. Toxoplasma seroconversion with negative or transient immunoglobulin $\mathrm{M}$ in pregnant women: myth or reality? A French multicenter retrospective study. J Clin Microbiol. 2013 Jul;51(7):2103-11. http://dx.doi.org/10.1128/JCM.00169-13 PMID:23616461

7. Kaye A. Toxoplasmosis: diagnosis, treatment, and prevention in congenitally exposed infants. J Paed Health Care. 2011 NovDec;25(6):355-64. http://dx.doi.org/10.1016/j.pedhc.2010.04.008 PMID:22018426

8. Almogren, A. Antenatal screening for Toxoplasma gondii infection at a tertiary care hospital in Riyadh, Saudi Arabia. Annals Saudi Med. 2011 Nov-Dec;31(6):569-72. http://dx.doi.org/10.4103/0256-4947.87090 PMID:22048499

9. Montoya J, Remington J. Management of Toxoplasma gondii infection during pregnancy. Clin Infec Dis. 2008 Aug 15;47(4):554-66. http://dx.doi.org/10.1086/590149 PMID:18624630

10. Torgerson PR, Mastroiacovo P. The global burden of congenital toxoplasmosis: a systematic review. Bull World Health Org. 2013 Jul 1;91:501-8. http://dx.doi.org/10.2471/BLT.12.111732 PMID:23825877

11. Ayi I, Edu S, Apea-kubi K, Boamah D, Bosompem K, Edoh D. Sero-epidemiology of toxoplasmosis amongst pregnant women in the greater Accra region of Ghana. Ghana Med J. 2009 Sep;43(3):107-14. http://dx.doi.org/10.4314/gmj.v43i3.55325 PMID:20126322

12. Shin D, Cha D, Hua Q, Cha G, Lee Y. Seroprevalence of Toxoplasma gondii infection and characteristics of seropositive patients in general hospitals in Daejeon, Korea. The Korean J Parasitol. 2009 Jun;47(2):125-30. http://dx.doi.org/10.3347/kjp.2009.47.2.125 PMID:19488418

13. Riyadh A Alzaheb. Seroprevalence of Toxoplasma gondii and its associated risk factors among women of reproductive age in Saudi Arabia: a systematic review and meta-analysis. Int J Womens Health. 2018 Sep 21;10:537-44. http://dx.doi.org/10.2147/IJWH. S173640 PMID:30288126

14. Mahdy M, Alareqi L, Abdul-Ghani R, Al-Eryani S, Al-Mikhlafy A, Al-Mekhlafi A, et al. A community-based survey of Toxoplasma gondii infection among pregnant women in rural areas of Taiz governorate, Yemen: the risk of waterborne transmission. Infect Dis Poverty. 2017 Feb 13;6(1):26. http://dx.di.org/10.1186/s40249-017-0243-0 PMID:28190399

15. Kirby T. Calls for more detailed studies on toxoplasmosis. Lancet Infect Dis. 2012 Dec;12(12):912-3. http://dx.doi.org/10.1016/s14733099(12)70303-1 PMID:23316490

16. Iqbal J, Khalid N. Detection of acute Toxoplasma gondii infection in early pregnancy by IgG avidity and PCR analysis. J Microbiol. 2007 Nov;56(11):1495-99. http://dx.doi.org/10.1099/jmm.0.47260-o PMID:17965351

17. Aqeely H, El-Gayar EK, Khan DP, Najmi A, Alvi A, Bani I, et al. Seroepidemiology of Toxoplasma gondii amongst pregnant women in Jazan Province, Saudi Arabia. J Trop Med. 2014;2014:913950. http://dx.doi.org/10.1155/2014/913950. PMID:25484905

18. Nahouli H, El Arnaout N, Chalhoub E, Anastadiadis E, El Hajj H. Seroprevalence of anti-Toxoplasma gondii antibodies among lebanese pregnant women. Vector Borne Zoonotic Dis. 2017 Dec;17(12):785-90. http://dx.doi.org/10.1089/vbz.2016.2092 PMID:29064352

19. Malary M, Hamzehgardeshi Z, Moosazadeh M, Afshari M, Ahmadi I, Moghaddasifar I, Motahareh K. Seroprevalence of Toxoplasma gondii infection among Iranian pregnant women: a systematic review and meta-analysis. East Mediterr Health J. 2018 Jun;24(5):488-96. http://dx.doi.org/10.26719/2018.24.5.488

20. Jumaian NF. Seroprevalence and risk factors for Toxoplasma infection in pregnant women in Jordan. East Mediterr Health J. 2005 Jan-Mar;11(1-2):45-51. https://apps.who.int/iris/handle/10665/116916. PMID: 16532670

21. Abu-Madi M, Behnke J, Dabritz H. Toxoplasma gondii seropositivity and co-infection with TORCH pathogens in high-risk patients from Qatar. Amer J Trop Med Hyg. 2010 Apr;82(4):626-33. http://dx.doi.org/10.4269/ajtmh.2010.09-0530 PMID:20348511

22. Hany MI, Azza HM, Ahmed AEl-S, Hend EEl-S. Molecular and serological prevalence of Toxoplasma gondii in pregnant women and sheep in Egypt. Asian Pac J Trop Med. 2017 Oct;10(10):996-1001. http://dx.doi.org/10.1016/j.apjtm.2017.09.012 PMID:29111196

23. Murebwayire E, Njanaake K, Ngabonziza J, Jaoko W, Njunwa K. Seroprevalence and risk factors of Toxoplasma gondii infection among pregnant women attending antenatal care in Kigali, Rwanda. Tanzania J Health Res. 2017; 19(1). http://dx.doi.org/10.4314/ thrb.v19i1.x

24. Frimpong C, Makasa M, Sitali L, Michelo C. Seroprevalence and determinants of toxoplasmosis in pregnant women attending antenatal clinic at the university teaching hospital, Lusaka, Zambia. BMC Infect Dis. 2017 Jan 5;17(1):10-8. http://dx.doi. org/10.1186/s12879-016-2133-7 PMID:28056829 
25. El-sayed MN, Almannoni AS. Seroprevalence of Toxoplasma gondii infection and associated risk factors among pregnant women in Sebha region, Libya. Inter J Allied Med Sci Clin Res. 2016;4(3):383-91. http://ijamscr.online/sites/default/files/articles/IJAMSCR-16-308_383-391.pdf

26. Mizani A, Alipour A, Sharif M, Sarvi S, Amouei A, Shokri A, et al. Toxoplasmosis seroprevalence in Iranian women and risk factors of the disease: a systematic review and meta-analysis. Trop Med Health. 2017 Apr 12;45:7-20. http://dx.doi.org/10.1186/ s41182-017-0048-7 PMID:28413330

27. Elsafi SH, Al-Mutairi WF, Al-Jubran KM, Abu Hassan MM, Al Zahrani EM. Toxoplasmosis seroprevalence in relation to knowledge and practice among pregnant women in Dhahran, Saudi Arabia. Path Global Health. 2015;109(8):377-82. http://dx.doi.org/10. 1080/20477724.2015.1103502 PMID:26924348

28. Nijem KI, Al-Amleh S. Seroprevalence and associated risk factors of toxoplasmosis in pregnant women in Hebron district, Palestine. East Mediterr Health J. 2009 Sep-Oct;15(5):1278-84. PMID:20214142

29. Smereka J, Szarpak L, Ruetzler K, Schacham Y, Smereka A, Dabrowski M, et al. A multicenter survey on toxoplasmosis knowledge among pregnant women in Poland (the TOWER study). BMC Preg Childbirth. 2018 Oct 3;18:389-93. http://dx.doi.org/10.1186/ S12884-018-2031-7. PMID:30285660 